\title{
«El espíritu de banda» versus el ideal humanístico: los años treinta en Francia
}

\author{
Constanza Eugenia TrujILlo AmayA \\ Universidad Complutense de Madrid \\ cetrujilloa@gmail.com
}

\begin{abstract}
RESUMEN
La obra de Jules Romains Les hommes de bonne volonté aborda un imaginario que distinguió, en parte, la mentalidad de una juventud francesa defraudada por la clase política y excedida por la masificación social y cultural. «El espíritu de banda» se refiere al de las Ligas, grupos de choque de carácter pseudo-militar, tanto de derecha como de izquierda, que salieron a la luz en las postrimerías de los años veinte en Francia. Al lado de estas bandas, la preocupación humanista por lo que debería ser el ideal europeo se afianzó frente al temor del nazismo creciente en Alemania y del fascismo en Italia. Años más tarde, en medio de la Segunda Guerra Mundial, este discurso humanístico tendría a uno de sus más grandes referentes en el escritor Albert Camus, a través de Lettres à un ami allemand. Los dos textos se refieren a un discurso social omnipresente en la sociedad francesa de los años treinta; y, permiten entender la mentalidad colaboracionista de aquella época.
\end{abstract}

Palabras clave: bandas, Ligas, entreguerras, Francia, humanismo, fascismo, nazismo.

\section{«Gang Spirit» versus the Humanistic Ideal: the 1930s in France}

\begin{abstract}
Jules Romains's work Les hommes de bonne volonté deals with an imaginary that exemplified, in part, the mentality of a sector of French youth betrayed by the political class and overrun by social and cultural mass effect. «Gang spirit» refers to the Leagues, pseudo-military groups, on both the far right and the far left, that appeared in France during the latter years of the twentieth decade. Alongside these "gangs», humanist concerns for what the European ideal should stand for gained a foothold in the face of fears about the growing Nazism movement in Germany and fascism in Italy. Years later, in the middle of the Second World War, this humanistic discourse would find one of its greatest exponents in writer Albert Camus and his Lettres à un ami allemand. Both texts refer to an omnipresent social discourse in 1930s French society, and enable us to understand the collaborationist mentality of that era.
\end{abstract}

Keywords: gangs, Leagues, between the wars, France, humanism, fascism, Nazism. 
El objetivo de este artículo es el de entrever -a partir de la lectura de un texto de Jules Romains, y la mención, a manera de conclusión, de uno de Albert Camus- el discurso político y social que reinaba en Francia en vísperas de la Segunda Guerra Mundial. Un texto literario puede recrear una realidad, pero no es el puro «reflejo» de una época histórica determinada, aunque sí permite entender el ambiente, las sensibilidades, el imaginario que la hayan podido caracterizar. De esta manera, a pesar de la reelaboración que ejercen los escritores sobre los acontecimientos a los cuales aluden, es posible hacer una aproximación al periodo en cuestión, desde diferentes enfoques, a saber: el socio-histórico, por ejemplo. La lectura crítica-sociocríticaque he llevado a cabo se centra en detallar aquellos aspectos sociales y políticos que, a mi juicio, tuvieron más relevancia en el desarrollo de ciertas mentalidades, durante la época de entreguerras, en Francia.

Jules Romains fue un escritor humanista, europeísta convencido, filósofo y colaborador de la Sociedad de Naciones (SDN), durante los años veinte. Les hommes de bonne volonté, evoca, en uno de sus relatos, «Naissance de la bande», el imaginario social y político que contribuyó a la exacerbación de un discurso de extrema derecha, con rasgos fascistas. Las bandas, como el autor las denomina en su extensa novela, recuerdan las denominadas Ligas que tomaron preponderancia en Francia, durante el período de entreguerras. El escritor pretendía recrear, a través de la trama novelística, el conjunto de la realidad socio-política de su país a lo largo de más de dos décadas: desde 1908 hasta 1933, año del epílogo de la novela. La obra comprende veintisiete relatos, divididos en el mismo número de tomos. Este artículo se centrará en «Naissance de la bande» y muy brevemente, para concluir, evocaré algunos apartes de «Le 7 octobre», el último de ellos.

Albert Camus, por su parte, militó en uno de los grupos de Resistencia francesa y se pronunció contra la embestida nazi y la invasión de gran parte del territorio francés, durante la Segunda Guerra Mundial. Sus célebres cartas, Lettres à un ami allemand (cuatro en total), fueron escritas entre 1943 y 1944, y publicadas en un periódico creado por el escritor, Combat, durante esos años de ocupación. Sin embargo, solo adquirieron relevancia cuando salieron a la luz a comienzos de los años cincuenta, con una aclaración del autor, en la que precisa que su interlocutor imaginario debía entenderse como un joven nazi de esos tiempos.

Los textos mencionados evocan una realidad histórica y social que caracterizó la época de entreguerras, en Francia, como se ha mencionado. Los personajes, las tramas, los argumentos y los conflictos son imaginarios, pero, a pesar de este carácter literario de las obras, los rasgos de los personajes, las huellas de los discursos sociales, las imágenes utilizadas para recrear situaciones y conflictos pueden identificarse con ciertas peculiaridades de la mentalidad política y social de aquella época, particularmente en París, la cual correspondió, en gran medida, a una élite intelectual y política durante esos años previos a la Segunda Guerra Mundial.

El relato «Naissance de la bande», de Les hommes de bonne volonté, alude a una creciente crisis social, política y económica que condujo a una decepción generalizada, por parte de la sociedad, de sus líderes políticos y de sus propuestas. Dichas circunstancias facilitaron el crecimiento de ideas y de grupos radicales, cuyas características se asemejan a aquellas enarboladas por el fascismo y el nazismo en esos años. 
El «espíritu de banda» al que se refiere el texto de Romains recuerda el brío del que se nutrían las denominadas Ligas, de orden político, en Francia. Estos grupos afloraron en las postrimerías del siglo XIX y tomaron ímpetu en la década de los veinte (Berstein 1991: 61), cuando el llamado Bloc national ${ }^{1}$ (1919-1924) fracasó (Becker y Berstein 1988: 242)2. Las Ligas desempeñaron un papel decisivo en el desarrollo de los acontecimientos políticos en Francia durante los años treinta, cuando hubo una proliferación de grupos de todo orden, particularmente en el ámbito político. París fue la cuna de una efervescencia asociativa. Este delirio gregario se difundió como consecuencia del fenómeno de masificación que vivió la sociedad parisina de la época (Milza 1987: 44-45). La migración masiva hacia la capital ocasionada por la centralización, la industrialización y la Primera Guerra Mundial contribuyó a un sentimiento de desarraigo y empobrecimiento agravado por la crisis económica y la incapacidad de los políticos para responder a las necesidades de la población y conformar un gobierno duradero (Loubet del Bayle 1979: 206).

De esta manera se generó un sentimiento antiparlamentario, en el cual se focalizaron todos los problemas que para entonces padecía la sociedad francesa. Los gobiernos, de derecha con el Bloc national primero, y luego uno de izquierdas con el Cartel de gauches, se sucedieron unos a otros, incapaces de dar respuestas convincentes a los problemas que agobiaban a los franceses. Esta situación propició el auge de ideales radicales que enarbolaron jóvenes decepcionados de los partidos políticos tradicionales, ávidos de oportunidades y, sobre todo, atraídos por un imaginario importado de la situación política que vivían Italia y Alemania. Las bandas, cuyo imaginario recrea el relato de Jules Romains, no esgrimían reivindicaciones claras ni mucho menos un programa político definido. Se caracterizaban por ser grupos de choque, que se disimulaban detrás de la violencia, una voluntad de anonimato y una cierta opacidad de sus líderes, quienes actuaban en diferentes frentes. Su objetivo era quebrantar el orden y exacerbar las sensibilidades a flor de piel, como consecuencia de la inquietante situación económica, política y social.

Estas bandas respondieron a un «estilo de vida» que se difundió y cuyas principales características eran el culto al cuerpo, el gusto por la escenificación de carácter militar, el deleite con los himnos, el aprecio a los uniformes, la pasión por relaciones lujuriosas entre los mismos sexos con objeto de estrechar vínculos entre los partidarios, así como el culto al jefe carismático y autoritario, quien promovía la acción, la mayoría de las veces violenta. Todas estas características fueron izadas por los movimientos fascistas y nazis (Milza 1987: 10). La mentalidad de las bandas se nutría de un discurso social impregnado por un sentimiento de camaradería y entusiasmo por conspirar en grupo. La banda conformaba también un cuerpo en el sentido simbólico, que hacía ondear sus banderas, izaba sus emblemas y marchaba

1 Una coalición entre conservadores y socialistas de centro.

2 De acuerdo a estos historiadores: «En una primera etapa el gobierno fue liderado por el radicalsocialista Heriot, quien fue sucedido por Briand. Este último fracasó en su política financiera, razón por la cual fue reemplazado por un gobierno de unión nacional, encabezado por Poincaré, en 1926» (Becker y Berstein 1988). Dando lugar, de esta manera, a la creación del Cartel des gauches. 
a la par. Como diría Sigmund Freud, el espíritu de las bandas en los años de entreguerras tuvo como motor de acción la transgresión, que encontraba su fuerza en el sentimiento gregario que fomentaban estas bandas (Freud 1993: 54). Sin embargo, el debate en torno a la existencia de un fascismo francés de entreguerras ha perseguido a historiadores y políticos de esa nación durante décadas (Berstein 1993: 68). Si bien la gran mayoría de ellos ha manifestado su incredulidad frente a la posibilidad de la existencia de semejante fenómeno dentro de la sociedad francesa, sin duda fueron muchos los rasgos que las Ligas de derecha compartieron con las llamadas juventudes nacionalistas del lado este del Rin.

Particularmente, en «Naissance de la bande» sobresale un imaginario relacionado, por una parte, al escenario político-social antes descrito y, por otro, al simbolismo de algunas bandas. Ahora bien, el texto refunde muchos de estos rasgos; recrea y anticipa acontecimientos, como lo hace, en general, la creación artística.

El telón de fondo del escenario político de entreguerras fue el enfrentamiento entre varias ideologías: las unas, conservadoras, nacionalistas, monárquicas; las otras, comunistas, socialistas e internacionalistas. Las jerarquías conservadoras de los años veinte temían un retorno del sentimiento anticlerical de principios de siglo y el cuestionamiento de los ideales patrióticos de los antiguos combatientes, que los habían llevado al campo de batalla durante la Primera Guerra Mundial. Muchos de estos simpatizantes se agruparon alrededor de Charles Maurras, escritor y político francés que constituyó el movimiento de Action française, también conocido bajo sus siglas AF. Este movimiento político nacionalista y antisemita nació en 1898, en pleno caso Dreyfus $^{3}$. Años más tarde, Maurras reivindicó, por un lado, sus pretensiones monárquicas; por otro, durante la ocupación, se volvió colaboracionista con el régimen de Vichy 4 .

Entre los movimientos considerados como Ligas, en Francia, podemos citar los siguientes, de los cuales da cuenta el imaginario de la novela. Primero, Le Faisce$a u$, creado por Georges Valois ${ }^{5}$, después de haber roto con Action française. Agrupó, sobre todo, a antiguos combatientes de la Primera Guerra Mundial. Fue un movimiento de corta duración (actuó entre 1925 y 1928). Segundo, Jeunesses patriotes (1924-1936), surgió contra el Cartel de gauches (1924-1926), que en ese momento dirigía el gobierno. Se caracterizó por sus rasgos abiertamente fascistas, bajo el liderazgo de Pierre Taittinger. Tercero, Parti populaire français (1936-1945) fue fundado por Jacques Doriot. Una gran mayoría de historiadores coincide en señalar a este partido como literalmente fascista (Milza 1987: 171-173). Doriot había sido miembro del Partido comunista francés, pero también se había declarado, en un momento, pacifista. Sin embargo, colaboró, sin ambigüedad, con el régimen de Vichy.

3 Alfred Dreyfus fue un militar francés de orígenes judíos, acusado de traición a la patria, al haber filtrado documentos secretos al entonces Imperio alemán, en 1898. El caso dejó huella durante más de una década en la sociedad francesa, cuyos miembros se dividieron entre dreyfusards y antidreyfusars.

${ }^{4}$ El régimen de Vichy fue presidido por el Mariscal Pétain (héroe de la Primera Guerra Mundial). Entre 1940 y 1944, mostró una progresiva condescendencia por las ideas de Hitler, llegando a acceder en prácticamente todos los requerimientos que este dictador le impuso.

5 George Valois, fundador del primer movimiento francés que se autoproclamó abiertamente como fascista, perteneció a los seguidores de Maurras, en un primer momento. 
Frente a las masas y al «espíritu de banda» se erguían, orgullosos pero desprovistos de sostén, los partidos tradicionales, que las nuevas generaciones percibían abstractos, convencionales, pero sobre todo, inoperantes y corruptos (Loubet del Bayle 1979: 198). Lo que resalta en el discurso social, al cual hace referencia la novela de Jules Romains, es el descontento frente a una burguesía por lo demás inmóvil ante las dificultades, viciosa y desapacible frente a la crisis.

«Naissance de la bande», el relato número veintitrés de Les hommes de bonne volonté, recrea esta efervescencia -mezcla de frustración política y social, irrupciones de nuevos actores, cambios económicos y movimientos sociales- a la cual los franceses se vieron abocados, desde finales de los años veinte. Esta segunda década del siglo pasado fue un periodo de excesos y locura, más conocida como les années folles, al menos, para los miembros de ciertas esferas sociales acomodadas, que terminó abruptamente, con el estallido de la crisis económica mundial. En especial, los jóvenes encontraron -en las ideologías en boga- refugio, incentivo para distinguirse de sus mayores y estímulo necesario para impulsar lo que denominaron un nuevo orden, un ordre nuveau ${ }^{6}$. Otros grupos también reivindicaban este concepto, entre ellos los viejos combatientes - anciens combattants - de la Primera Guerra Mundial. Decepcionados por su situación de abandono y por una política lánguida frente a la creciente amenaza nazi, promulgaban el regreso a los viejos ideales patrióticos que, en su mayoría, habían idealizado. Pensaban que era la única forma de «salvar» la situación y que para regresar al viejo orden era necesario crear uno nuevo. Tal razonamiento provocó muchos malentendidos. El lema-controvertido sin duda- fue utilizado ampliamente por partidos, revistas y movimientos sociales de todo orden, sin percatarse, en muchos casos, de las contradicciones.

Este ambiente social que caracterizó los años treinta en Francia daría pie, en gran medida, a una mentalidad colaboracionista con el régimen nazi, que invadió buena parte del hexágono francés durante la Segunda Guerra Mundial. El traumatismo que este drama significó para la sociedad francesa hizo que durante largo tiempo esta situación fuera renegada por una amplia mayoría (Loubet del Bayle 1979: 111).

En «Naissance de la bande», el personaje Gilbert Nodiard es el líder de una banda que denominó AA - estas recuerdan las siglas de Action française, AF-. La principal obsesión de este joven líder era la de que sus seguidores obedecieran sus planes, sin discusiones ni debates. Para él, la discusión de un programa político resultaba algo engorrosa, significaba pérdida de tiempo y de energías. El perfil de Nodiard puede relacionarse con el del dirigente de Jeunesses patriotes, Pierre Taittinger. Este último comparte con el personaje de Romains los rasgos de prepotencia,

${ }^{6}$ Este término es altamente confuso, dependiendo de quién es el interlocutor, pues Hitler lo utilizó para designar al nuevo hombre que debería regir los destinos de la humanidad, de acuerdo a sus ideales nazis. También es el nombre de una revista que vio la luz en Francia, bajo la dirección de Robert Aron. No obstante como señala el historiador Jean-Louis Loubet del Bayle: «En ella se expresaba el sentimiento de un malestar con el régimen y todo tipo de ideas que llenaban las planas de su modesto periódico. Sin embargo, a partir de 1933, la revista promovió el movimiento Ordre Nouveau, en el que se confunden rasgos tanto de la izquierda comunista como de la derecha gregaria» (Loubet del Bayle 1979: 111). 
arbitrariedad y autoritarismo. Esta Liga funcionó en la realidad como un grupo de choque, que brindaba servicios a otras bandas, y cuyos miembros se reconocían en la acción violenta. Para Nodiard, lo más importante era marcher ensemble-caminar juntos-. Argumentaba que «si l'on discute et discute, avec l'espérance que, chacun ayant bien vidé son paquet, l'accord finira pour sortir de la discussion elle-même, on tombe en plein parlementarisme, dans tout la sottise, le vice et l'impuissance du parlementarisme» (Romains 1988: 251).

Nodiard, al igual que Taittinger, se sentía abrumado cuando sus simpatizantes le reclamaban más claridad respecto a un programa, unos objetivos, unas reglas. Aseguraba:

Le mal dont on avait réussi à se préserver depuis le début, le bavardage à n'en plus finir sur les principes, sur le programme, sur les règles de recrutement, sur l'attribution des fonctions et dignités, toute cette imitation puérile de ce qu'on s'était juré d'abattre, allait donc infecter ce petit groupe si peu de temps après sa naissance... (Romains 1988: 256)

Nodiard no soportaba la idea de la herencia francesa du siècle des lumières, que promovía el debate de ideas, la ciencia y el conocimiento. Pensaba que el pueblo francés había sido contaminé jusqu'aux moelles. Nodiard quería tener unos adeptos incondicionales que siguieran ciegamente sus órdenes y que tuvieran tanto recursos económicos como relacionales para promover sus acciones, e involucrarse fácilmente en el ámbito de aquellos que tomaban las decisiones. Al igual que Taittinger, Nodiard investigaba las capacidades de cada uno de los aspirantes. Repudiaba la idea de tener un grupo numeroso, prefería una pequeña célula que tuviera amplia capacidad de acción. Nodiard no creía en la democracia ni en la importancia de la participación. De ahí su discurso:

... vous sacrifiez tous aux illusions démocratiques. Vous croyez encore au nombre. Si nous avions donné trois ou quatre meetings de mille personnes, rassemblées au petit bonheur par voie d'affiches; si nous avions fait, également au petit bonheur, deux ou trois mille adhésions, de gens qui ne penseraient à nous qu'au moment de payer leur cotisations, vous crieriez victoire. [...] Les masses se conquièrent en surplus, en un tournemain, quand le travail est fait. Et il ne se fait pas dans les masses. (Romains: 1988: 259)

En suma, Nordiard quería que su banda fuera una especie de Estado Mayor, cuyos adeptos tuvieran relaciones con los miembros del parlamento y del gobierno, a fin de influir en la toma de decisiones. Pero, por otro lado, se contradecía, declaraba que un Estado Mayor solo nunca había ganado una guerra, y que por lo tanto era necesario un grupo de un centenar de miembros, para lo cual tuvieron que integrar un personaje decisivo llamado Douvrin, en la novela. Este último puede ser asociado, por un lado, con Jacques Doriot, y por otro, con Georges Valois. El primero fundó el Parti populaire français en los años treinta, exactamente en 1936; fue el único partido reconocido como verdaderamente fascista. Jacques Doriot había sido obrero y había militado en las filas del Parti communiste français hasta que fue 
excluido en 1934, debido a sus divergencias con Moscú. Por su parte, Georges Valois fungió como uno de los líderes de Action française hasta que fundó en 1925 Le Faisceau.

En la realidad, tanto Action française como el Parti populaire français tuvieron algunos cientos de seguidores. En el texto de la novela, Nodiard, fundador de la banda AA., aspira a utilizar estas fuerzas porque entre sus seguidores se cuentan al quelques centaines de costauds, dispuestos a pasar a la acción, según su discurso. Señalaba que:

Pour moi, Douvrin et sa bande sont un des servomoteurs éventuels. Car sa bande [...], n'a fait que croître et embellir. C'est d'ailleurs assez mystérieux. J'ai tâché de me renseigner. Combien sont-ils ? Pas un chiffre énorme. Un millier au plus; répartis en une certaine quantité de petites bandes locales, [...]. Mais des gaillards solides; des hommes de main. (Romains 1988: 262)

Los miembros de la banda de Nodiard, las AA, en la novela, desconfiaban de las intenciones de un líder como Douvrin, quien había militado en el Parti communiste français. Sospechaban que este caudillo pudiera obedecer órdenes directamente de Moscú. En realidad, los dirigentes de las Ligas, en Francia, temían que Moscú prefiriera «une nullité obéissante à un garçon de valeur, que sa valeur même rendait dangereux» (Romains 1988: 264).

Ahora bien, recordemos que los adeptos del «espíritu de banda» reivindicaban el entusiasmo por la condición natural, la connivencia con la naturaleza; admiraban la belleza corporal y el bienestar físico, desconfiaban del desarrollo técnico, para la época, y de las grandes megalópolis. El fascismo defendía la idea del heroísmo y el estrechamiento de las relaciones, a través de prácticas sexuales. Promovían encuentros en los que suscitaban las experiencias orgiásticas con el fin de garantizar la unidad del grupo, como si se tratara de una comunión. En el relato «Naissance de la bande», Nodiard calculaba que el conocimiento del otro pasaba por una experiencia íntima, que debía considerarse como un rito de iniciación. Señalaba, por ejemplo: «notre faiblesse principale à nous Français: c'est la peur de s'emballer, la peur d'être dupe, la peur de prendre les choses au sérieux, la peur du ridicule... l'ironie comme argument préalable» (Romains 1988: 292).

Para Nodiard, como para algunos admiradores de los valores fascistas, entre los que se contaron intelectuales y escritores ${ }^{7}$, las relaciones sexuales se inscribían en una determinada visión del mundo, un «estilo de vida», que - de acuerdo con esta filosofía- debería revolucionar el concepto del amor, tal cual como lo mencionara Bataille, quien tenía en mente, según Habermas, «la idea de una política «estetizada», poética, purificada de todos los elementos morales. Y eso es lo que seduce en el fascismo» (Habermas 1989: 265-266).

En el discurso de la novela, Nodiard argumentaba que era una vida digna de explorarse, y que con seguridad la época que se avecinaba iba a estar marcada por

${ }^{7}$ Entre ellos se puede citar, por ejemplo, a Pierre Drieu La Rochelle. 
ese «estilo de vida»: «el espíritu de banda». Evocaba con sus amigos una experiencia junto a las juventudes nacional-socialistas, en Alemania, durante los años veinte. Estaba convencido de que los nazis iban a tomar el poder. De este modo refería su experiencia a sus camaradas:

Donc une époque de bandes petites ou grandes, mais fortement organisées, liées par le fer et le feu, par la chair de sang. Des bandes sont en trains de refaire le monde actuel un peu partout, de s'emparer du pouvoir, et du vrai pouvoir [...]. Je dis que ces bandes ont besoin d'être cimentées à l'intérieur non par de vagues idées ou de vagues programmes, mais par des choses vitales, des choses de passion et de chair. Il n'y a rien de plus vital que le sexe ; de plus fort pour lier des êtres que le sexe. Tu te rappelles que je suis allé en Allemagne l'été dernier. [...] Tu sais combien j'ai été frappé par ces bandes... que j'ai eu la chance d'approcher de près. Les nazi, comme on les appelle par abréviation. Ils m'ont accueilli. [...] je suis convaincu que leurs bandes ont pour lien profond l'homosexualité. Ils ne sont probablement pas tous des homosexuels pratiquants. Mais ce qui charpente l'ensemble, ce qui lui fournit son dynamisme, c'est la passion charnelle du mâle pour le mâle. Et cette passion les unit non par couples, mais par groupes, par bandes. (Romains 1988: 307)

Frente a la creciente importancia que tomaron estas bandas, o Ligas en el contexto francés, muchos intelectuales se agruparon, en torno a la prensa -revistas y periódicos, algunos esporádicos, pero otros sobrevivieron los avatares políticos y las crisis económicas-. Entre los más renombrados, destacan Esprit ${ }^{8}$, Ordre Nouveau ${ }^{9}$, Cahiers, La Revue française, La Revue du siècle ${ }^{10}$. Estas publicaciones manifestaban su preocupación y su desacuerdo con el auge -según ellos- de ideas inquietantes, impulsadas por los líderes de las bandas. Un espíritu humanístico se izó, como una bandera, contra la creciente simpatía por las ideas fascistas en la juventud francesa.

Dos personajes de la novela de Jules Romains encarnan ese ideal humanístico: Jallez, narrador-protagonista de la novela, y Jerphanion, quien personifica la imagen de un político de la vieja data, vinculado a las instancias gubernamentales de la época. Para estos personajes, lo relevante en el discurso de entonces era la difusión de las ideas humanísticas. Era necesario actuar, pero de otra manera: organizarse a través de organismos como la Sociedad de Naciones (SDN) que, según él, operaba a imagen y semejanza de las antiguas órdenes de caballería.

En una larga disquisición, semejante a la reflexión que puede ofrecer un diario, Romains recuerda lo que para entonces había sido el sueño de una Europa humanística. Lo hace en el último relato de la novela, el número veintisiete, cuyo título es «Le 7 Octobre», por medio de su personaje Jallez, escritor y antiguo funcionario

\footnotetext{
8 Fundada por Emmanuel Mounier en 1931.

9 Fundada por Robert Aron en 1933, tuvo vida durante pocos meses.

10 Alrededor de estas tres revistas gravitó la disidencia intelectual de derecha del movimiento Action française, que generó el grupo conocido como Jeune droite, bajo el impulso de Jean de Fabrègues y Thierry Maulnier, principalmente. Algunas estas revistas tuvieron una muy corta duración.
} 
de la Sociedad de Naciones, al igual que Jules Romains. Como muchos políticos, académicos e intelectuales de la época, Jallez debatía con su amigo Jerphanion sobre el significado de las campañas militares en suelo europeo, por ejemplo: la realizada por Napoleón Bonaparte, a finales del siglo XVIII y comienzos del XIX. Para Romains, en la voz de Jallez, Europa debía apartarse de la idea de conquista y opresión por medio de la bota militar y, en lugar de ello, recrear una herencia cultural, política y artística, legado de griegos y romanos. Jallez pregonaba los ideales de Apolo y de Prometeo. En otras palabras, apelaba a la difusión de las artes, la sabiduría, el conocimiento; evocaba l'esprit du siècle des lumières, según el cual se debía fomentar el debate, arguyendo razones y dejando de lado la fuerza, las armas y el absolutismo, y obrar en beneficio de la humanidad. Para Jallez, como para el autor, Europa debía ser un subcontinente donde pueblos de diversos orígenes, razas, culturas y creencias convivieran de manera pacífica.

Recordemos que, en esa época de entreguerras, muchos intelectuales franceses desconfiaban de sus colegas alemanes, como consecuencia de las guerras sucesivas, que habían pautado su convivencia de las dos naciones en las últimas décadas -la de 1870, cuando Francia perdió Alsacia y Lorena, y la Primera Guerra Mundial, cuando los franceses tomaron la revancha-. En suma, los franceses definían a los alemanes por su romanticismo, la música, un espíritu recóndito de la filosofía-siguiendo el razonamiento del personaje Jallez-, pero se mantenían apartados del discurso cartesiano y científico del cual se enorgullecían los galos, de acuerdo con la argumentación de Romains y de Albert Camus.

La gran diferencia entre la idea de una Europa al estilo nazi (bajo el yugo militar) y la concepción que de ella se forjaban los humanistas era que la primera deseaba el sometimiento total du siècle des lumières, mientras que la segunda promovía una Europa unida, en el respeto de la diferencia del otro, bajo la divisa de la razón, el conocimiento y la justicia. Albert Camus evoca esta última idea en Lettres à un ami allemand, en su segunda carta, fechada en diciembre de 1943. Para él, el espíritu humanístico, la inteligencia y el reconocimiento del otro poseen un lugar preponderante, por encima de los nacionalismos extremos o de la patria chica: «si parfois nous semblions préférer la justice à notre pays, c'est que nous voulions seulement aimer notre pays dans la justice, comme nous voulions l'aimer dans la vérité et dans l'espoir» (Camus 1965: 228).

Para Camus, como para muchos otros intelectuales, admiradores de los ideales humanísticos, como por ejemplo, Denis de Rougement, Europa debía ser una congregación de pueblos, reunidos en el respeto del uno por el otro, en el reconocimiento de las diferencias culturales, en la consideración de las tradiciones de cada uno. Así escribía Camus en la tercera carta, fechada en abril de 1944:

Vous dites Europe, mais vous pensez terre à soldats, grenier à blé, industries domestiquées, intelligence dirigée. Vais-je trop loin ? [...] vous dites Europe [...] vous ne pouvez pas vous empêcher de penser à une cohorte de nations dociles menée par une Allemagne de seigneurs, vers un avenir fabuleux et ensanglanté. [...] Mais elle (Europe) est pour nous cette terre de l'esprit où depuis vingt siècles se poursuit la plus étonnante aventure de l'esprit humain. (Camus 1965: 21) 
Camus escribió estas cartas a un destinatario imaginario, siendo militante en la Resistencia, durante los peores momentos de la Segunda Guerra Mundial. Camus se definió en un primer momento como pacifista pero más tarde abandona este ideal. Lettres à un ami allemand muestra la voluntad de sobrepasar el absurdo de la guerra y redescubrir los valores comunes, a los pueblos europeos, principalmente entre Alemania y Francia.

\section{Referencias bibliográficas}

ANTLIFF, Mark (2012): «Fascismo de vanguardia en Francia». Revista de Literatura y Pensamiento 5: 23-35.

BECKER, Jean-Jacques y BERSTEIN, Serge (1988): Victoire et frustrations (1914-1929). París: Seuil.

BersteIn, Serge y Milza, Pierre (1991): Histoire de la France au XXème siècle. París: Complexe, 2 vols.

BERSTEIN, Serge (1993): La France des annés 30. París: Armand Colin.

CAMus, Albert (1965): «Lettres à un ami allemand», en Essais. Colección La Pléiade, pp. 219-250. París: Gallimard3

FREUD, Sigmund (1993): Psicología de las masas. México: Alianza.

HABERMAS, Jürgen (1989): El discurso filosófico de la modernidad. Madrid: Taurus.

LOUBET DEL BAYLE, Jean-Louis (1979): Les non-conformistes des années 30. París: Seuil. MiLZA, Pierre (1987): Fascisme français, passé et présent. París: Flammarion.

ROMAINS, Jules (1988): «Naissance de la bande», in Les hommes de bonne volonté. Colección Bouquins, vol. IV, pp. 193-373. París: Robert Laffont.

- (1988): «Le 7 octobre», en Les hommes de bonne volonté. Colección Bouquins, vol. IV, pp. 930-1124. París: Robert Laffont. 